\title{
Programa de Residência Multiprofissional em Saúde: o que mostram as publicações
}

\author{
Multiprofessional Health Residency Program: what publications show
}

\author{
Cinthia Alves da Silva', Maristela Dalbello-Araujo'
}

DOI: $10.1590 / 0103-1104201912320$

RESUMO O artigo aborda o Programa de Residência Multiprofissional em Saúde (PRMS), através da revisão bibliográfica de 25 artigos, publicados entre 2010 e 2015. A maioria dos artigos vem da região Sudeste do Brasil, foi publicada em 2015 e é fruto de dissertações e teses. Os artigos confirmam a hegemonia do modelo biomédico na saúde e a precarização das condições de trabalho e estrutura dos serviços, fatores que impactam as relações estabelecidas entre residentes e demais trabalhadores, produzindo inúmeros questionamentos sobre a formação e a prática profissional através dos PRMS. É importante dizer que as estratégias para enfrentamento dessas problemáticas e para transformação da realidade também são destacadas nos artigos, evidenciando confiança nas potencialidades dos PRMS e do SUS como política pública e direito a ser defendido.

PALAVRAS-CHAVE Programas de pós-graduação em saúde. Capacitação de recursos humanos em saúde. Internato e residência.

ABSTRACT The article addresses the Multiprofessional Health Residency Program (PRMS), through the bibliographical review of 25 articles, published between 2010 and 2015. Most of the articles come from the Southeast region of Brazil, was published in 2015 and is the result of dissertations and theses. The articles confirm the hegemony of the biomedical model inhealth and the precariousness of the working conditions and service structure, factors that impact the relations established between residents and other workers, producing numerous questions about the training and the professional practice through PRMS. It is important to say that the strategies for coping with these problems and for transforming reality are also highlighted in the articles, evidencing confidence in the potential of PRMS and SUS as public policy and the right to be defended.

KEYWORDS Health postgraduate programs. Health human resource training. Internship and residency. 


\section{Introdução}

A partir dos anos 1980, ocorreram transformações intensas e importantes nos sistemas de saúde nacionais do Ocidente, onde, segundo Campos et al.', a área de recursos humanos foi fortemente afetada, no sentido de ocorrerem modificações nas modalidades de contratação dos trabalhadores, na forma da organização do trabalho e na composição das equipes. Simultaneamente, surgiu a necessidade de aprimorar a maneira como se desenvolvem os recursos humanos em saúde.

No caso do Brasil, as demandas que incidem sobre o Sistema Único de Saúde (SUS) ocorrem em diversas áreas. No que se refere ao trabalho, destacam-se a gestão de variadas formas de contratação, a gestão descentralizada, o trabalho em equipe, entre outros. Tais transformações demonstram a necessidade de

[...] conceber, implementar e institucionalizar alternativas de educação permanente tanto para a formação de profissionais quanto para seu aprimoramento em serviço $[\ldots]^{\mathbf{2 ( 3 9 )}}$.

A rotina dos serviços de saúde e as relações que se operam, no sentido de realizar a gestão e o cuidado em saúde, são centrais para a construção de processos formativos com vistas a enfrentar os desafios postos à consolidação do SUS e da integralidade como seu princípio, o que pressupõe a necessidade de mudanças no processo de trabalho. Frente às políticas de formação profissional que (re)produzem a fragmentação dos saberes e práticas em saúde, entende-se que a interferência nos modos instituídos de produzir cuidado demanda a problematização das ações de formação e gestão vigentes. Requer tomar os processos de trabalho em seus limites e potencialidades como vetor fundamental na constituição dos processos de formação, uma vez que abordar as práticas de cuidado e de gestão em saúde implica compreender a multiplicidade que as constitui².

Nesse contexto, as Residências Multiprofissionais em Saúde (RMS) ganharam destaque, sendo coordenadas pelos Ministérios de Educação (MEC) e da Saúde (MS). Conforme esclarecem Silva e Capaz ${ }^{3}$, as RMS têm o potencial da interdisciplinaridade, unindo em um mesmo espaço de formação e trabalho diversos saberes e fazeres que devem caminhar rumo à integralidade das ações em saúde ofertadas à população. As RMS promovem interação entre gestores, profissionais dos serviços, profissionais residentes, docentes e usuários, além de aproximarem os campos da saúde e da educação. Assim, o Programa de Residência Multiprofissional em Saúde (PRMS) surge como estratégia para a reorganização dos serviços públicos embasado nos princípios do SUS.

Tendo em vista que um dos princípios do SUS diz respeito à integralidade que orienta a diagnose e as terapêuticas para além dos aspectos puramente físicos ou biológicos, o PRMS, ao contar com a presença de profissionais de diferentes áreas do conhecimento, intenta contribuir para a produção de mudanças no modelo biomédico de atenção à saúde. Modelo esse hegemônico no Ocidente e que exclui da compreensão do processo saúde-doença aspectos importantes, tais como o psicológico e o social, com forte ênfase no locus hospitalar. Nesse sentido, o PRMS visa, ainda, a constituir-se como um programa de cooperação intersetorial para favorecer a inserção dos jovens profissionais da saúde no mercado de trabalho, promovendo mudanças na sua formação ${ }^{4}$.

Embora a regulamentação do programa tenha ocorrido em 2005, através da promulgação da Lei $n^{\circ} 11.129$, cabe destacar que somente dois anos depois foi instituída a Comissão Nacional de Residência Multiprofissional (CNRMS), regulamentada pela Portaria Interministerial MEC/MS n ${ }^{\circ}$ $45 / 2007^{5}$. Essa portaria foi revogada pela Portaria Interministerial $\mathrm{n}^{0} 1.077 / 2009^{6}$, que, posteriormente, foi alterada pela Portaria Interministerial $1.224 / 2012^{7}$. A partir da criação da CNRMS, foram realizados seminários regionais e nacionais e fóruns coletivos, 
com a participação de diversos atores envolvidos com o Programa, o que possibilitou a elaboração de propostas direcionadoras para seu funcionamento. Tais encontros perduram como momentos de construção e discussão para aperfeiçoamento dos PRMS na atualidade. Além da concepção ampliada de saúde, preconiza-se a rede de serviços como espaço de aprendizagem, propondo o trânsito dos residentes pelas diferentes instituições que compõem as linhas de cuidado nas quais se inserem. A proposta é deslocar o foco de atenção das patologias para as áreas de cuidado, buscando promover a integralidade na atenção à saúde. Para tanto, propõe-se a integração ensino-serviço e a integração de saberes, por meio de um núcleo pedagógico básico comum a todos os profissionais ${ }^{8}$.

O PRMS ousa, ao dar importante contribuição no sentido de integrar saberes, possibilitar a vivência nos diferentes serviços que compõem a rede de atenção à saúde e contribuir para criar espaços facilitadores das reflexões sobre prática profissional, relações institucionais, interpessoais e com os usuários. $\mathrm{O}$ que se pretende é promover mudanças na atenção à saúde, buscando a integralidade das ações prestadas em acordo com uma política de educação permanente para a formação de trabalhadores para o SUS.

No entanto, a conjuntura não se mostra favorável à implantação dos PRMS. O sucateamento das instituições, a precarização e a privatização dos serviços, a chegada da Empresa Brasileira de Serviços Hospitalares (EBSERH) como gestora dos Hospitais Universitários Federais (HUs), a sobrecarga de trabalho para os profissionais dos serviços, o risco de exploração da mão de obra dos residentes, entre outros, são elementos que impactam diretamente a condução dos programas ${ }^{8}$. Esse cenário afeta diretamente a prática profissional dos residentes e trabalhadores dos serviços, interferindo na consolidação do PRMS.

Registra-se, ainda, mais efetivamente a partir de 2009, a vinculação dos PRMS aos HUs, objetivando um modelo de atenção integral à saúde e o atendimento à demanda por profissionais de saúde especialistas em áreas prioritárias para o SUS $^{9}$. Esse movimento trouxe questões importantes para a consolidação dos programas e para o debate acerca da formação de recursos humanos para o sistema de saúde. Desse modo, esta pesquisa buscou identificar o que os artigos publicados entre os anos de 2010 e 2015 apresentam sobre o PRMS, destacando os principais elementos que perpassam o cotidiano das instituições e o trabalho de residentes e profissionais dos serviços na trajetória de construção do PRMS. O recorte temporal proposto foi definido através de breve busca inicial que evidenciou o referido período como suficiente para reunir publicações que contribuíssem para alcançar o objetivo deste estudo.

\section{Metodologia}

Este estudo foi realizado por meio de revisão bibliográfica. A pesquisa bibliográfica, nas palavras de Sá-Silva et al..$^{10}$, diferencia-se de outros métodos por ser um estudo que recorre diretamente às fontes científicas, sem buscar os fenômenos da realidade empírica. A função dessa metodologia de pesquisa é propiciar aos pesquisadores o contato direto com a produção que trata do tema a ser pesquisado.

A busca dos artigos foi realizada nos bancos de dados SciELO (Scientific Electronic Library Online) e Bireme (Centro Latino-Americano e do Caribe de Informação em Ciências da Saúde), utilizando filtros referentes ao idioma, ano de publicação, tipo de publicação, país de origem e disponibilidade do documento. Foram selecionados apenas artigos em português, publicados entre os anos de 2010 e 2015, no Brasil, e disponibilizados na íntegra. O critério de inclusão foi a presença das palavras 'Residência', 'Multiprofissional' e 'Multidisciplinar' no título. Entretanto, considerando que títulos lúdicos, isto é, aqueles que não trazem tais palavras devido à menção a músicas, poesias e/ou metáforas, também 
poderiam se referir ao PRMS. Verificaram-se tais palavras também nos resumos. Os critérios para exclusão foram: tratar de Residência Uniprofissional e abordar as equipes multiprofissionais compostas apenas pelos trabalhadores dos serviços que ofertam os campos de prática ao PRMS.

Vale destacar a inexistência do descritor 'Residência Multiprofissional' no site de Descritores em Ciências da Saúde (DeCS) da Biblioteca Virtual em Saúde (BVS). Por isso, entre os descritores disponíveis, foram selecionados os que contemplavam a temática da RMS: 'Equipe de Cuidados de Saúde'; 'Equipe de Saúde'; 'Programas de Pós-Graduação em Saúde'; 'Prática Profissional'; 'Trabalhadores da Saúde'; 'Educação' e 'Internato e Residência'. Para além dos descritores especificados, fez-se uma busca utilizando 'Residência Multiprofissional em Saúde', especificando a procura por 'todos os índices' e por 'título, resumo, assunto'.

Tabela 1. Descritores utilizados e quantidade de artigos encontrados

\begin{tabular}{|c|c|c|c|c|c|c|}
\hline \multirow[t]{2}{*}{ Descritores } & \multicolumn{3}{|c|}{ SciELO } & \multicolumn{3}{|c|}{ Bireme } \\
\hline & Busca & Excl. & Incl. & Busca & Excl. & Incl. \\
\hline Equipe de Cuidados de Saúde & 206 & 202 & 4 & 407 & 400 & 7 \\
\hline Equipe de Saúde & 899 & 894 & 5 & 421 & 414 & 7 \\
\hline $\begin{array}{l}\text { Programas de Pós-Graduação em } \\
\text { Saúde }\end{array}$ & 75 & 74 & 1 & 38 & 36 & 2 \\
\hline Prática Profissional & 348 & 344 & 4 & 381 & 380 & 1 \\
\hline Trabalhadores da Saúde & 666 & 663 & 3 & 1.082 & 1.072 & 10 \\
\hline Educação & 1.994 & 1.981 & 13 & 1.683 & 1.676 & 7 \\
\hline Internato e Residência & 8 & 7 & 1 & 46 & 44 & 2 \\
\hline $\begin{array}{l}\text { Residência Multiprofissional em Saúde } \\
\text { ('todos os índices') }\end{array}$ & 45 & 27 & 18 & - & - & - \\
\hline $\begin{array}{l}\text { Residência Multiprofissional em Saúde } \\
\text { ('título, resumo, assunto') }\end{array}$ & - & - & - & 10 & 3 & 7 \\
\hline Total & 4.241 & 4.192 & 49 & 4.068 & 4.025 & 43 \\
\hline Leitura de resumo & & & 92 ar & & & \\
\hline
\end{tabular}

Fonte: Elaboração própria.

Todos os 92 artigos incluídos tiveram os resumos lidos, e, seguindo os critérios de inclusão e exclusão anteriormente determinados, chegou-se a um número final de 25 artigos analisados. Buscou-se extrair das publicações alguns elementos previamente definidos em um quadro, a fim de organizar as principais questões abordadas pelos autores. Tal procedimento possibilitou uma visão geral das principais questões tratadas nas publicações, permitindo a identificação de três grandes categorias: 'Trabalhadores e processo de trabalho', 'Organização e funcionamento do PRMS' e 'Aspectos Estruturais das instituições/campos de prática do PRMS'. Construiu-se a análise a partir dessas três categorias, reunindo em grupos as publicações que dialogam, majoritariamente, sobre as mesmas questões. Dos 25 artigos analisados, 14 discutem 'Trabalhadores e Processo de Trabalho'; 9 abordam 'Organização e Funcionamento do PRMS'; e 'Aspectos estruturais das instituições/campos de prática dos PRMS' comparecem em 2 dos artigos. 


\section{Resultados e discussão}

A maioria das publicações é proveniente da região Sudeste do Brasil, o que coincide com a distribuição dos PRMS no País e corrobora os dados de Dallegrave e Ceccim"1.

A pesquisa também revelou que os residentes pouco publicam sobre suas vivências durante a inserção nos programas. Dos artigos selecionados, metade é produto de dissertações e teses, não sendo possível identificar em todos os artigos se os autores foram residentes. Acerca dessa questão, podemos considerar a possibilidade de um amadurecimento maior sobre as experiências no PRMS ocorrer após a vivência, o que torna a inserção em mestrados e doutorados uma oportunidade para estudar o tema. A mesma percepção pode justificar o volume maior de publicações no ano de 2015, já que, a partir de 2009, o PRMS passa por um redirecionamento importante, conforme assinalado anteriormente. Apenas 1 artigo, entre os que foram analisados, resulta do Trabalho de Conclusão de Curso (TCC) do $\mathrm{PRMS}^{12}$, e alguns questionamentos parecem pertinentes: quais têm sido os formatos de TCC utilizados nos PRMS? Existe algum meio para divulgação dos trabalhos? A produção e a publicação de artigos são incentivadas pelos PRMS?

Quadro 1. Principais características das publicações incluídas na pesquisa

\begin{tabular}{|c|c|c|c|}
\hline LOCAL & $\begin{array}{l}\text { Sudeste - } 13 \text { artigos } \\
\text { Sul - } 8 \\
\text { Nordeste - } 3 \\
\text { Centro-oeste - } 1 \\
\text { Norte- } 0\end{array}$ & ANO & $\begin{array}{l}2015 \text { - } 12 \text { artigos } \\
2013 \text { - } 5 \\
2010 \text { e } 2014 \text { - } 3 \text { cada } \\
2012 \text { - } 2 \\
2011 \text { - } 0\end{array}$ \\
\hline PERIÓDICOS & $\begin{array}{l}\text { Interface (Botucatu) - } 5 \text { artigos } \\
\text { Trabalho, Educação e Saúde - } 2 \\
\text { Psicologia Ciência e Profissão - } 2 \\
\text { Saúde e Sociedade - } 2 \\
\text { Revista Gaúcha de Enf. - } 2 \\
\text { Revista de TO da USP - } 2 \\
\text { Revista da Escola de Enf. da USP - } 2 \\
\text { Periódicos diversos (um em cada) - } 8\end{array}$ & $\begin{array}{l}\text { AUTORES/ } \\
\text { FORMAÇÃOO }\end{array}$ & $\begin{array}{l}\text { Fruto de teses e dissertações - } 14 \\
\text { artigos } \\
\text { Não identificados - } 5 \\
\text { Professores e residentes - } 4 \\
\text { Preceptores e professores - } 1 \\
\text { TCC da Residência (TO) - } 1\end{array}$ \\
\hline ÁREA & $\begin{array}{l}\text { Enfermagem - } 7 \text { artigos } \\
\text { Não identificada - } 7 \\
\text { Duas ou mais categorias - } 4 \\
\text { Terapia Ocupacional - } 3 \\
\text { Psicologia - } 2 \\
\text { Nutrição - } 1 \\
\text { Odontologia - } 1\end{array}$ & TIPO & $\begin{array}{l}\text { Qualitativo - } 23 \text { artigos } \\
\text { Quantitativo - } 1 \\
\text { Quali/quanti - } 1\end{array}$ \\
\hline
\end{tabular}

Fonte: Elaboração própria.

TO: Terapia Ocupacional; Enf.: Enfermagem; USP: Universidade de São Paulo.

\section{Trabalhadores e processo de trabalho}

Os artigos agrupados neste eixo discutem as relações de trabalho com as quais os residentes se deparam em seu processo formativo. Essa realidade também atinge os/as trabalhadores/ as dos serviços/campos de prática e se operam na complexidade das interações que se estabelecem no processo de trabalho.

Os artigos apontam como limites: a terceirização e a instabilidade dos contratos de trabalho, resultando em fragilidade de vínculos; 0 
número reduzido de profissionais nas instituições; e a ausência de bolsas para preceptoria, além de esta atividade ser considerada mais uma atribuição dentro da carga horária dos profissionais. Apontam, ainda, a dificuldade de diálogo entre trabalhadores e pacientes; tarefas administrativas vistas como desvio de função; expectativa sobre algumas categorias profissionais para a atuação clínica individual; dificuldade para o exercício do trabalho coletivo; discursos e posturas corporativistas; resistência por parte de equipes antigas nos serviços; e ausência de aprendizado sobre gestão, redes e macrogestão ${ }^{12,13}$.

Apesar dos limites encontrados impactarem diretamente o trabalho dos residentes, é prudente observar que poucos são, especificamente, originários do PRMS. O Programa acaba por ser um agente que põe em evidência os aspectos estruturais que limitam o trabalho em saúde, bem como suas potencialidades. Não se pode esquecer que o PRMS está inserido em uma lógica macropolítica que contém determinantes estruturais intrínsecos e que impactam objetivamente a política de saúde nas diversas esferas em que se realiza.

Especificamente sobre os residentes, alguns estudos enfatizam os impactos do trabalho e das relações institucionais e interpessoais na saúde e no processo formativo. Além do estresse do cotidiano de trabalho, os residentes se deparam com a exaustão vivida anteriormente na graduação e que continua e/ou aumenta com as atribuições acadêmicas e laborais na Residência. As más condições de trabalho; baixa remuneração; limitações para participação em eventos científicos; falta de motivação por parte dos profissionais dos serviços para desenvolver novas atividades; carga horária elevada; falta de tempo para estudo e pesquisa; designação para 'substituir' profissionais do serviço; cobranças de produtividade; falta de identidade profissional; ausência de espaços para questionamentos junto aos/as preceptores/as, tutores/as e equipes de saúde; falta de reconhecimento do trabalho realizado; falta de articulação entre aprendizado teórico, orientações recebidas e práticas instituídas nos serviços; e, ainda, o desafio de romper com a reprodução social de práticas hegemônicas foram citados entre os principais elementos estressores ${ }^{12-14}$.

Conforme aponta Mendes ${ }^{15}$, o trabalho não pode tornar-se lugar só de sofrimento ou só de prazer, ele resulta da dinâmica interna das situações e da organização do trabalho, ou seja,

[...] tanto o modelo de organização do trabalho prescrito pela organização, como as relações subjetivas dos trabalhadores com o trabalho têm papel fundamental na determinação de vivências de prazer, com consequências para a produtividade ${ }^{15(36)}$

Diante disso, é necessário criar espaços de diálogo entre os PRMS e os serviços/campos de prática ${ }^{16}$. No caso da formação em saúde através do PRMS, Guido et al. ${ }^{17}$ destacam que podemos considerar alguns aspectos como estressores por seu caráter inovador, ou seja, estão na contramão dos modelos vigentes de ensino. No caso do PRMS, pode-se destacar: trabalho em equipe, metodologias ativas e participativas, relações entre categorias profissionais diversas e a responsabilização por um cuidado integrado e humanizado a ser alcançado pela mudança de práticas já solidificadas nos serviços.

Outro aspecto bastante evidenciado nas publicações refere-se à fragilidade da formação acadêmica para a atuação na saúde. Muitos residentes tiveram pouca ou nenhuma aproximação com a saúde pública antes da Residência. O trabalho dos profissionais é descrito como desarticulado e fragmentado devido à ausência de espaços de discussão e diálogo, e as discussões que ocorrem no horário de trabalho são consideradas 'informais', ou seja, não são vistas como trabalho. Também são realizadas poucas abordagens grupais; há dificuldade para trabalhar em equipe e pouca capacitação para o trabalho de promoção e prevenção em saúde, ao mesmo tempo que há cobrança desse tipo de ação ${ }^{18-28}$. 
Os artigos também mostram que algumas categorias profissionais enfrentam desafios específicos durante o processo formativo da Residência, são elas a fonoaudiologia, a psicologia, a nutrição e a terapia ocupacional. Os artigos citam como comum às quatro categorias a ausência de uma formação acadêmica em consonância com o SUS, bem como a expectativa dos profissionais de outras categorias para a atuação especializada/individual no nível secundário de atenção à saúde. Isso dificulta a construção do processo de trabalho desses profissionais na Atenção Primária (AP), já que, nesse nível de atenção, impõem-se fortemente a necessidade de intervenções grupais, a compreensão social dos problemas enfrentados e o trabalho em equipe multiprofissional. Outro problema evidenciado pelos artigos é o baixo número de publicações sobre a atuação desses profissionais na AP, agravado pela ausência de diretrizes para o trabalho - mais especificamente no que se refere à nutrição e à fonoaudiologia. Os residentes enfrentam, ainda, a ausência de profissionais contratados nessas áreas, o que o que os leva a 'suprir' a falta desses trabalhadores ${ }^{\mathbf{1 3 , 1 9 - 2 2}}$.

Acerca dessa problemática, Mendes ${ }^{8}$ destaca que, nos fóruns de discussão sobre a Residência, há uma queixa generalizada quanto à sobrecarga de trabalho, que é resultado, entre outros fatores, do baixo número de profissionais para atender às demandas da população. A autora esclarece, ainda, que, somado a essa questão, que independe da existência da Residência, a implantação dos PRMS trouxe novas demandas aos profissionais, entre elas, a preceptoria, tutoria, coordenação geral e de área e, ainda, a docência das disciplinas.

Tais requisições, contudo, não se fizeram acompanhar pela melhoria das condições de trabalho e, especialmente, pela contratação de novos trabalhadores ${ }^{\mathbf{8}(\mathbf{1 9 3})}$.

Todavia, embora os artigos assinalem muitos limites para o trabalho e para as relações que os trabalhadores estabelecem através da atuação profissional no PRMS, os autores também destacam potencialidades que, em grande parte, referem-se às estratégias para o enfrentamento das dificuldades encontradas no cotidiano de trabalho. Os estudos demonstram que os processos de trabalho construídos através do PRMS possibilitam aprendizado constante do diálogo, da política das relações sociais e adoção de atitudes defensivas diante do medo e da instabilidade do mundo do trabalho ${ }^{23}$. Ao final do processo formativo, sentimentos iniciais de incompetência e desvalorização são substituídos por reconstrução pessoal, profissional e de competências ${ }^{17}$. O quadro 2 permite observar as principais potencialidades do PRMS destacadas pelos artigos quanto ao eixo 'Trabalhadores e processo de trabalho'.

Quadro 2. Potencialidades do PRMS e conclusões dos artigos do eixo 'Trabalhadores e processo de trabalho'

\begin{tabular}{ll}
\hline \multirow{2}{*}{$\begin{array}{l}\text { Identificação do } \\
\text { Potências do PRMS }\end{array}$} & Título: Residência na Atenção Básica à saúde em tempos líquidos \\
\cline { 2 - 3 } & Autor(es): Rossoni E \\
\hline & - Desender a administrar incertezas. 2015 \\
& - Estímulo a ações defensivas diante do medo e da instabilidade do mercado de trabalho. \\
& - Criar brechas para atitudes solidárias. \\
& - Coletivo como forma de resistência. \\
Conclusões do artigo & - A repetida questão de o trabalho na ABS/APS ser considerado de baixa complexidade perpetua pouca ou nenhuma valori- \\
& zação a quem se dedica a esses serviços. \\
& - Necessidade de qualificar estruturas físicas e processos de trabalho nos serviços. \\
& - Rever formas de contratação dos profissionais, privilegiando estabilidade, plano de carreira e remuneração adequados. \\
\hline
\end{tabular}


Quadro 2. (cont.)

\begin{tabular}{|c|c|}
\hline \multirow{2}{*}{$\begin{array}{l}\text { Identificação do } \\
\text { artigo }\end{array}$} & Título: Síndrome de Burnout em residentes multiprofissionais de uma universidade pública \\
\hline & Autor(es): Guido LA, Silva RM, Goulart CT, et al. \\
\hline Potências do PRMS & $\begin{array}{l}\text { - No final de períodos da residência, sentimentos iniciais de incompetência e desvalorização são substituídos por recons } \\
\text { ção pessoal, profissional e de competências. } \\
\text { - Os enfermeiros destacam que quase todas as atividades que Ihe são confiadas correspondem à sua qualificação. } \\
\text { - Buscando evitar situações desconfortáveis, residentes assumem pacientes mais graves e também gerenciam unidades } \\
\text { que resulta em maior autoconfiança e habilidade técnica. }\end{array}$ \\
\hline Conclusões do artigo & $\begin{array}{l}\text { - Os residentes estão expostos a elementos estressores que podem favorecer o surgimento da Síndrome de Burnout. } \\
\text { - Ocorre a cronificação do estresse, que é multicausal e pode ter início na graduação. } \\
\text { - Há residentes com indicativo de Burnout, e prevalecem adultos jovens e enfermeiros. } \\
\text { - Indivíduos jovens podem apresentar menos habilidades para superar o desgaste de situações profissionais e pessoais. } \\
\text { - Necessário desenvolver atividades educativas e de orientação sobre estratégias de enfrentamento e Burnout. }\end{array}$ \\
\hline
\end{tabular}

\begin{tabular}{ll}
\hline Identificação do & Título: Sofrimento e prazer no processo de formação de residentes multiprofissionais em saúde \\
\cline { 2 - 3 } & Autor(es): Fernandes MNS, Beck CLC, Weiller TH, et al. \\
\hline Potências do PRMS & - RMS desencadeia processo de construção da integralidade das ações nos serviços. \\
& - Trabalho em equipe multiprofissional associado ao prazer profissional. \\
& - PRMS 'desacomoda' o serviço. \\
& - Possibilidade de reinvenção diária do trabalho dinamizada pela experimentação do conflito vivenciado na realidade dos \\
& serviços.
\end{tabular}

Conclusões do artigo - As situações de sofrimento parecem se sobressair com relação às possibilidades de prazer.

- Necessidade de espaços de diálogo entre os Programas e os serviços de saúde, a fim de integrar trabalhadores e residentes.

- Necessidade de construir um processo de formação que favoreça aprendizado e bem-estar dos residentes.

- Necessário realizar novos estudos em outros cenários, a fim de que se possa confrontar, rediscutir e ampliar resultados.

\section{Identificação do artigo}

Potências do PRMS
Título: Percepcão dos residentes sobre sua atuação no programa de residência multiprofissional Autor(es): Silva JC, Contim D, Ohl RIB, et al.

Ano: 2015

- Residência como possibilidade de conhecimento de outras categorias profissionais que se complementam.

- Realização de ações conjuntas e desenvolvimento de habilidades de reconhecer outras necessidades dos pacientes sabendo encaminhá-los a outros profissionais.

- Preservação da especificidade, mas vendo o multiprofissional como benefício para o paciente.

- Aceitação e reconhecimento por parte dos pacientes, favorecendo o reconhecimento do papel profissional.

- Assistência qualificada que contribui para a adesão ao tratamento.

- Construção coletiva do conhecimento e desenvolvimento de uma proposta inovadora de assistência.

Conclusões do artigo - PRMS como oportunidade significativa de aprendizado e contato com profissionais de diferentes áreas, permitindo assumir nova conduta profissional.

- A assistência ao usuário adquire caráter mais humanizado e abrangente através do compartilhamento de conhecimentos específicos de cada área e participação nas atividades de saúde.

\begin{tabular}{ll} 
Identificação do & Título: A Comunicação entre a equipe de saúde em uma clínica cirúrgica: o olhar dos profissionais de um PRMS \\
\cline { 2 - 2 } artigo & Autor(es): Aredes MA, Bahia LA, Silva CSMC, et al. \\
\hline
\end{tabular}

Potências do PRMS - PRMS possibilitou a observação de atitudes e ações dos profissionais envolvidos na assistência da clínica cirúrgica = observação da comunicação profissional-profissional, profissional-paciente, profissional-familiar e paciente-familiar.

- Comunicação entre profissionais tornou-se ferramenta constante para discussão, planejamento, reavaliação de condutas e modificação da visão acerca do paciente e de sua doença.

- Ações dos residentes com objetivo de reduzir tempo de permanência do paciente, custos hospitalares, prevenção de complicações.

- Comunicação entre profissionais, pacientes e familiares favorece a confiança e auxilia no tratamento e na qualidade da assistência.

Conclusões do artigo - Comunicação articula profissionais, pacientes e familiares, e é essencial durante o tratamento.

- RMS tem se destacado como programa de treinamento para o trabalho em equipe, facilitando o processo de trabalho.

- Experiência possibilitou aos residentes aprender questões relevantes a cada área e ao trabalho articulado, tendo na comuni-

cação ferramenta integradora do conhecimento e melhorando a qualidade do atendimento.

- Importância da comunicação em encontros para discussão de casos e troca de informações para melhora na assistência e no prognóstico do paciente. 
Quadro 2. (cont.)

\begin{tabular}{ll}
\hline $\begin{array}{l}\text { Identificação do } \\
\text { artigo }\end{array}$ & $\begin{array}{l}\text { Título: ‘A gente vai aprendendo': o apoio matricial na estratégia de saúde da família em um programa de } \\
\text { residência multiprofissional integrada no interior do Rio Grande do Sul, Brasil }\end{array}$ \\
\cline { 2 - 3 } & Autor(es): Brites LS, Weiller TH, Sileira D, et al. \\
\hline Potências do PRMS & - PRSM contribui para a formação de profissionais para o SUS, no arranjo do Apoio Matricial e Saúde da Família. \\
& - As práticas de matriciamento desenvolvidas pelos residentes, embora tímidas, foram se solidificando com a atuação na \\
& realidade local. \\
Conclusões do artigo & - Desafios incentivam os sujeitos a construir estratégias de enfrentamento das dificuldades encontradas. \\
& - Importância da prática na experimentação da proposta de Apoio Matricial. \\
& - Permitir essa experimentação aos residentes e profissionais caracterizou-se como diferencial para conseguir mudanças nos \\
& processos de trabalho no SUS. \\
& - Necessário, mas não suficiente oferecer suporte teórico nos PRMS. É preciso permitir participação ativa dos profissionais \\
& residentes e dos serviços, da gestão da residência, do município e dos usuários na efetivação de um canal permanente de \\
& discussão para operacionalização do Apoio Matricial na ESF. \\
\hline
\end{tabular}

\begin{tabular}{ll}
\hline $\begin{array}{l}\text { Identificação do } \\
\text { artigo }\end{array}$ & Título: Competências Profissionais e o Processo de Formação na Residência Multiprofissional em Saúde da Ano: 2010 \\
& Família
\end{tabular}

Autor(es): Nascimento DDG, Oliveira MAC

Potências do PRMS - RMSF apresenta potencialidades pedagógicas e políticas para transformação do modelo de atenção à saúde da família.

- Compreensão de que a escuta ampliada e o acolhimento são indispensáveis para a atenção à saúde.

- Reconhecimento do trabalho como local de produção do saber na ESF, o que foi reforçado pelo PRMS.

- Reconhecimento de formação generalista para atuação na ESF (conhecimento sobre políticas públicas, processo saúde-

-doença, Atenção Primária, interdisciplinaridade, saúde coletiva, referência e contrarreferência).

Conclusões do artigo - Necessário atentar para a importância do gerenciamento do tempo, do trabalho e dos recursos disponíveis.

- Reorganização da AP nos moldes da ESF requer renovação de práticas, vínculos e compromissos de corresponsabilidade entre serviços de saúde e usuários.

- Na ESF, a educação em saúde torna-se instrumento de conscientização e de superação de vulnerabilidades.

- Um dos desafios para os profissionais no cotidiano do trabalho é reconhecer e respeitar a autonomia das pessoas com relação ao seu modo de vida, reafirmando compromisso com a integralidade e a humanização.

- A construção desse perfil de competências evidenciou a necessidade de pensar a formação no PRMS a partir de uma perspectiva ampliada do processo saúde-doença, assim como refletiu as competências desejáveis para atuar na ESF por meio da imersão pelo e no trabalho, oportunizada pela RMS.

\begin{tabular}{ll}
\hline $\begin{array}{l}\text { Identificação do } \\
\text { artigo }\end{array}$ & Título: Potencialidades da Residência Multiprofissional em Saúde da Família: o olhar do trabalhador da saúde Ano: 2015 \\
\cline { 2 - 3 } & Autor(es): Domingos CM, Nunes EFPA \\
\hline
\end{tabular}

Potências do PRMS A inserção da RMSF favorece integralidade das ações em saúde; amplia relação teoria-prática; potencializa a USF como dispositivo de mudança no modelo de assistência à saúde; avanço do trabalho multiprofissional; inclusão de diversas categorias profissionais que não atuavam na USF; amplia o conhecimento dos trabalhadores sobre o território e dados epidemiológicos - melhor planejamento em acordo com as necessidades da comunidade; presença dos residentes como apoio na prestação do cuidado, troca de conhecimentos - discussão de casos/tomada de decisão, melhora na capacidade resolutiva da equipe. Contribuição para a formação do residente: vivência no cotidiano de uma USF; desenvolvimento da habilidade de se relacionar com o usuário e identificar a gama de dimensões que envolve os usuários; formação de profissionais capacitados para atuar na USF.

Os trabalhadores atribuem à residência a capacidade de 'trabalhar redondinho'. Resolutividade do trabalho da equipe em conjunto com os residentes minimiza a culpa quando não é possível atender o paciente. Residência contribuiu para a expansão da assistência em saúde bucal da população adulta e modificou o processo de trabalho da odontologia da USF. A RMSF possibilitou mais conhecimento sobre o SUS. Potencializa a educação permanente.

RMSF percebida como 'especialização para a vida'.

Conclusões do artigo RMSF evidenciou a insuficiência da equipe mínima da ESF.

RMSF impulsiona a ESF a ser um dispositivo de mudança no modelo de assistência à saúde.

Para os profissionais do serviço, a RMSF se mostrou como potente estratégia de formação de profissionais capacitados para atuar na ESF.

Fica evidente a necessidade da parceria ensino, serviço e comunidade para que a RMSF se confirme como uma das possíveis estratégias de mudança na formação.

RMSF é uma ferramenta para operar o proposto pela Educação Permanente na formação inacabada dos profissionais de saúde. Projeto Político-Pedagógico da RMSF condizente com os princípios do SUS. 
As possibilidades que o PRMS aponta impactam o trabalho dos profissionais dos serviços, fortalecendo as ações desses trabalhadores. Tratando das especificidades das categorias profissionais, os residentes de áreas que enfrentam dificuldades para a atuação no PRMS também alcançam êxitos durante o processo formativo. Os artigos evidenciam que a inserção da fonoaudiologia, psicologia, nutrição e terapia ocupacional na AP possibilita o diagnóstico precoce de doenças e/ou agravos; favorece o desenvolvimento de atividades em acordo com as necessidades da comunidade; conhecimento sobre território e processo saúde-doença; compreensão da dimensão da promoção da saúde na prática profissional; integração com outras categorias profissionais; participação em instâncias de controle social e de gestão; construção de um novo perfil de profissional para atuar na Estratégia Saúde da Família (ESF); e favorece ações coletivas e menos individualizadas. Além disso, o trabalho em equipe amplia e qualifica o trabalho específico.

A inserção do PRMS na USF é citada como importante para a formação profissional, pois ajuda na melhora da postura profissional e na segurança a respeito da profissão ao final da Residência. $\mathrm{O}$ PRMS também tem influência para a inserção no serviço público, além de estimular ações em prol da melhora do currículo da graduação e a criação de diretrizes para o trabalho na $\mathrm{AP}$ - nos casos da fonoaudiologia e da nutrição ${ }^{12,13,9-20}$.

\section{Organização e funcionamento do Programa de Residência Multiprofis- sional em Saúde}

Com relação à dimensão organizacional e de funcionamento do PRMS, os artigos discutem processos avaliativos, preceptoria, processos ensino-aprendizagem hierarquizados, relação teoria e prática e Projetos Político-Pedagógicos (PPP) dos Programas.

Três estudos refletem sobre a utilização de metodologias avaliativas diferenciadas e de cunho mais participativo ${ }^{24-26}$. No entanto, a metodologia proposta também causa angústia nos residentes, considerando o fato de sua execução ser mais trabalhosa e reflexiva, o que se contrapõe à rotina de trabalho imposta pela Residência. Os artigos apontam, ainda, dificuldade em implementar ações coletivas; excesso de demandas de trabalho; separação entre pensar e fazer; e relações de hierarquia e subordinação entre preceptores e residentes.

No que concerne à preceptoria, os artigos destacam, de modo geral, que a ausência de formação para exercer essa atribuição e a falta de clareza sobre o papel do preceptor no processo formativo geram inúmeras dificuldades para a organização e o funcionamento dos programas, ficando a cargo de cada programa definir o que é a preceptoria e qual o papel do preceptor ${ }^{27}$. Nesse sentido, haveria uma insuficiência no conceito de preceptoria existente no PRMS.

Os artigos apontam, ainda, o preceptor com atividades de diversas ordens (técnica, docente, ética e moral); perspectiva pedagógica da preceptoria como geradora de desconforto nos preceptores, já que não são formados para tal atividade; acúmulo de atividades pelo preceptor, prejudicando a formação do residente; ausência de preceptores nos serviços, impactando a inserção dos residentes nesses espaços; preceptoria vista como 'função a mais'; docentes com visão hierarquizada do processo formativo; não avaliação dos preceptores pelos residentes; número reduzido de preceptores para as demandas dos campos de prática; e a existência de diversos tipos de atuação entre os preceptores - alguns acompanham sistematicamente, outros esporadicamente-, além do tempo insuficiente para a preceptoria ${ }^{28}$. Outros autores evidenciam que a opinião dos residentes não é considerada pelos preceptores; há falta de percepção do preceptor sobre o seu papel educativo; inadequação dos processos de supervisão e avaliação das atividades dos residentes e dissociação entre teoria e prática ${ }^{\mathbf{4 1 , 2 8}}$.

Para essas problemáticas, alguns artigos também apontam possíveis soluções e sugerem encontros periódicos entre coordenadores, docentes e outros preceptores para a troca de experiências, além da promoção de estratégias que invistam no autodesenvolvimento dos sujeitos como preceptores e profissionais em sua área. Constatou-se que o preceptor dispõe de pouco 
tempo para essa atividade e que sua participação restrita é sentida pelos residentes ${ }^{27,29}$.

É importante dizer, ainda, que não se trata apenas de capacitar preceptores para a atuação no PRMS. A preceptoria figura no cenário do trabalho em saúde como o elemento 'denunciador' da urgência da revisão dos processos de trabalho instaurados nas instituições de saúde. A atividade de preceptoria está imersa no emaranhado de relações que se estabelecem entre trabalhadores e entre estes e as dinâmicas das instituições.

A relação entre preceptor e residente deve ultrapassar a transferência de conhecimento e técnicas e deve ser uma relação dialética. É preciso notar que uma relação mais horizontalizada e colaborativa não 'funde' esses atores, mas abre espaço para a busca de mais conhecimento e de novas ideias. "É fundamental considerar preceptores e residentes como sujeitos em formação"3(214).

No campo da discussão sobre os Projetos Político-Pedagógicos (PPP) dos programas, os artigos revelam a ausência de uniformidade entre esses projetos, sendo encontradas várias formas de organização didática, diferentes matrizes pedagógicas e diversos sistemas de avaliação. Os PPP também não apresentam definições de multiprofissional e interprofissional, impedindo a identificação das concepções adotadas. Não há explicitação sobre os marcos teóricos adotados e há predomínio de uma visão restrita sobre preceptoria ${ }^{30}$.

Um estudo 28 aponta que ainda prevalecem métodos educativos convencionais, que priorizam o mero repasse de informações, a individualidade e a prática repetitiva. Nesse sentido, a adoção de metodologias ativas/reflexivas, especificamente o diário de campo, é apontada como valioso instrumento de gestão educacional e formação em saúde, propiciando uma avaliação global do residente, bem como auxiliando nas reflexões sobre a prática profissional cotidiana ${ }^{24}$. Mendes ${ }^{8}$ descreve as Residências como potência para repensar práticas profissionais consolidadas e refletir sobre a estruturação dos serviços, propondo transformações. Isso requer ferramentas pedagógicas que possibilitem ponderações e proposições. Segundo a autora, somente metodologias participativas, dialéticas e dialógicas possibilitam esses movimentos. Deve haver espaço para que os atores desse processo tenham liberdade para interrogar o cotidiano e propor soluções. No entanto, instituir essa liberdade requer relações mais horizontalizadas, que não são fáceis de serem criadas frente à hegemonia de algumas profissões de saúde.

Como alternativas a essa problemática, alguns artigos sugerem a construção de propostas de avaliação que deem conta do processo ensino-aprendizagem para além das atividades de ensino em serviço. Além disso, no que se refere ao Programa, estabelecer a prática de autoavaliação pode se constituir enquanto estratégia de aprimoramento ${ }^{25,30,31}$. Duas publicações ${ }^{24,26}$ destacam a adoção de metodologias ativas (diário de campo) como instrumento que auxilia na identificação do que é necessário aprender; propicia reflexão e melhora de competências e das práticas educacional e assistencial; fomenta o desenvolvimento da habilidade narrativa; ajuda na elaboração do TCC; serve como suporte para a preceptoria, ajudando a retomar questões relevantes; e ainda possibilita um olhar mais acadêmico sobre a formação.

Quanto aos aspectos positivos no âmbito da organização e do funcionamento do PRMS, uma publicação ${ }^{31}$ abordou a construção de indicadores para a avaliação do PRMS, especificamente, no campo da ESF, evidenciando que há uma preocupação em adequar os PPP aos princípios do SUS. O artigo avalia a construção de um instrumento de avaliação que busca contribuir para acompanhar a qualidade metodológica e pedagógica do Programa. Outro estudo ${ }^{30}$ aponta que a maioria dos programas adota um currículo integrativo, estruturado em eixos comuns a todas as categorias profissionais, além de existir nos programas uma prática sólida de avaliações dos residentes. No quadro 3, destacam-se as potencialidades acerca da preceptoria e demais componentes da organização e do funcionamento do PRMS citados nos artigos. 
Quadro 3. Potencialidades do PRMS e conclusões dos artigos do eixo 'Organização e funcionamento do PRMS'

\begin{tabular}{|c|c|c|}
\hline \multirow[t]{2}{*}{$\begin{array}{l}\text { Identificação do } \\
\text { artigo }\end{array}$} & $\begin{array}{l}\text { Título: Um relato de caso sobre a construção e elaboração do portfólio como metodologia avaliativa de } \\
\text { aprendizagem }\end{array}$ & \multirow[t]{2}{*}{ Ano: 2015} \\
\hline & Autor(es): Lana LD, Birner JA & \\
\hline Potências do PRMS & \multicolumn{2}{|l|}{$\begin{array}{l}\text { - Liberdade para a construção do portfólio. } \\
\text { - Presença da preceptora (que conhece a realidade vivenciada pelo residente) como avaliadora. } \\
\text { - Ciclo de troca entre preceptor e residente. } \\
\text { - Possibilidade de melhora prática assistencial, educacional e gerencial da RMS e da instituição. } \\
\text { - Interlocução com o Projeto Pedagógico do Programa para construção das reflexões. } \\
\text { - Oportunidade de relacionar o currículo com as atividades desenvolvidas. } \\
\text { - Maior interação entre residente e preceptor. Possibilita momentos de troca nas relações de trabalho. } \\
\text { - Aprendizado centrado nas competências, pois se aprende fazendo. Revela o preceptor como educador. }\end{array}$} \\
\hline Conclusões do artigo & \multicolumn{2}{|l|}{$\begin{array}{l}\text { - Deve haver disposição dos preceptores para adotarem metodologias inovadoras de avaliação. } \\
\text { - A utilização de um diário de campo ajuda a minimizar a demora na construção do portfólio. } \\
\text { - O portfólio é um instrumento facilitador para o desenvolvimento de habilidades e atitudes dos residentes. } \\
\text { - Há uma lacuna entre construção, avaliação e a prática desenvolvida pelo residente, pois as etapas são morosas. } \\
\text { - O desenvolvimento do portfólio contribui para o progresso da docência, pois é uma estratégia interessante de apropriação } \\
\text { da avaliação como componente do trabalho pedagógico, reflexivo e participativo. Possibilita pensar crítico do residente, com } \\
\text { vistas a mudar práticas tradicionais. } \\
\text { - Necessário realização de mais estudos sobre o uso do portfólio. Propõe que a metodologia do PRMS seja aperfeiçoada e } \\
\text { aponta o uso do portfólio como instrumento auxiliar da formação. }\end{array}$} \\
\hline \multirow[t]{2}{*}{$\begin{array}{l}\text { Identificação do } \\
\text { artigo }\end{array}$} & $\begin{array}{l}\text { Título: A experiência dos diários reflexivos no processo formativo de uma Residência Multiprofissional em } \\
\text { Saúde da Família }\end{array}$ & Ano: 2013 \\
\hline & \multicolumn{2}{|l|}{ Autor(es): Oliveira FGVC, Carvalho MAP, Garcia MRG, et al. } \\
\hline Potências do PRMS & \multicolumn{2}{|l|}{ - Possibilita aprendizado com a prática e a construção de saídas. } \\
\hline Conclusões do artigo & \multicolumn{2}{|c|}{$\begin{array}{l}\text { - Ferramenta eficaz de acompanhamento das atividades das equipes. Fornece subsídios para a avaliação dos residentes. } \\
\text { - Valioso instrumento da gestão educacional da formação em saúde. Propicia avaliação global do residente, considerando o } \\
\text { cognitivo, o psicomotor e o afetivo. } \\
\text { - Necessidade de maior viabilização de instrumentos dessa natureza, que se ancoram na prática crítica e reflexiva. } \\
\text { - Necessidade de aperfeiçoamento das experiências de uso do instrumento. Na saúde, os diários fortalecem a apreensão de } \\
\text { novas experiências de construção compartilhada do conhecimento. } \\
\text { - O diário é um instrumento com funções pedagógicas importantes. Auxilia no reconhecimento das necessidades de aprendi- } \\
\text { zagem, no desenvolvimento da competência narrativa e na reflexão continuada sobre as múltiplas dimensões da prática. } \\
\text { - O diário oportuniza debates que relacionam teoria e prática. Auxilia na confecção do TCC. } \\
\text { - Serve como suporte para as reuniões de orientação. Ajuda na identificação dos estágios do processo formativo. Auxilia na } \\
\text { memória de questões relevantes. }\end{array}$} \\
\hline \multirow[t]{2}{*}{$\begin{array}{l}\text { Identificação do } \\
\text { artigo }\end{array}$} & $\begin{array}{l}\text { Título: A preceptoria na formação médica e multiprofissional com ênfase na atenção primária - análise das } \\
\text { publicações brasileiras }\end{array}$ & Ano: 2015 \\
\hline & \multicolumn{2}{|l|}{ Autor(es): Autônomo FROM, Hortale VA, Santos GB, et al. } \\
\hline Potências do PRMS & $\begin{array}{l}\text { - Preceptor inserido na equipe facilita a mediação de conflitos. } \\
\text { - Preceptores como modelo para o crescimento e desenvolvimento pessoal e ético dos residentes. } \\
\text { - Presença contínua dos residentes provoca outro modo de operar desacomodando o instituído. } \\
\text { - Introdução da docência no serviço acentua a implicação com o trabalho e inaugura fluxos institucionais entre } 8 \\
\text { zacional e assistência clínica. } \\
\text { - Situações interdisciplinares possibilitam formação ampliada. Preceptores que foram residentes têm uma postu } \\
\text { da, pois lembram que também estão formando futuros preceptores. }\end{array}$ & stão organi- \\
\hline Conclusões do artigo & $\begin{array}{l}\text { - Necessidade de mais estudos sobre o preceptor e suas funções. } \\
\text { - Não foram encontrados um ou mais conceitos de preceptoria. Onde eram pra ser vistos conceitos, viram-se m } \\
\text { definição do que seja o preceptor e suas atribuições não demanda uma padronização, mas requer elucidação. } \\
\text { - O estudo possibilitou compreender que o profissional que assume uma preceptoria deve conhecer o programa } \\
\text { inserido, seus objetivos e o que esperam de sua participação; deve preparar a equipe que irá receber os resident } \\
\text { a inserção dos residentes na equipe; reservar um horário para a preceptoria; manter encontros periódicos com c } \\
\text { res, docentes e outros preceptores para troca de experiências; promover estratégias de aprendizagem; avaliar e } \\
\text { autoavaliação do residente; investir no autodesenvolvimento como preceptor e como profissional em sua área. }\end{array}$ & $\begin{array}{l}\text { táforas. A } \\
\text { em que será } \\
\text { S; estimular } \\
\text { ordenado- } \\
\text { stimular a }\end{array}$ \\
\hline
\end{tabular}




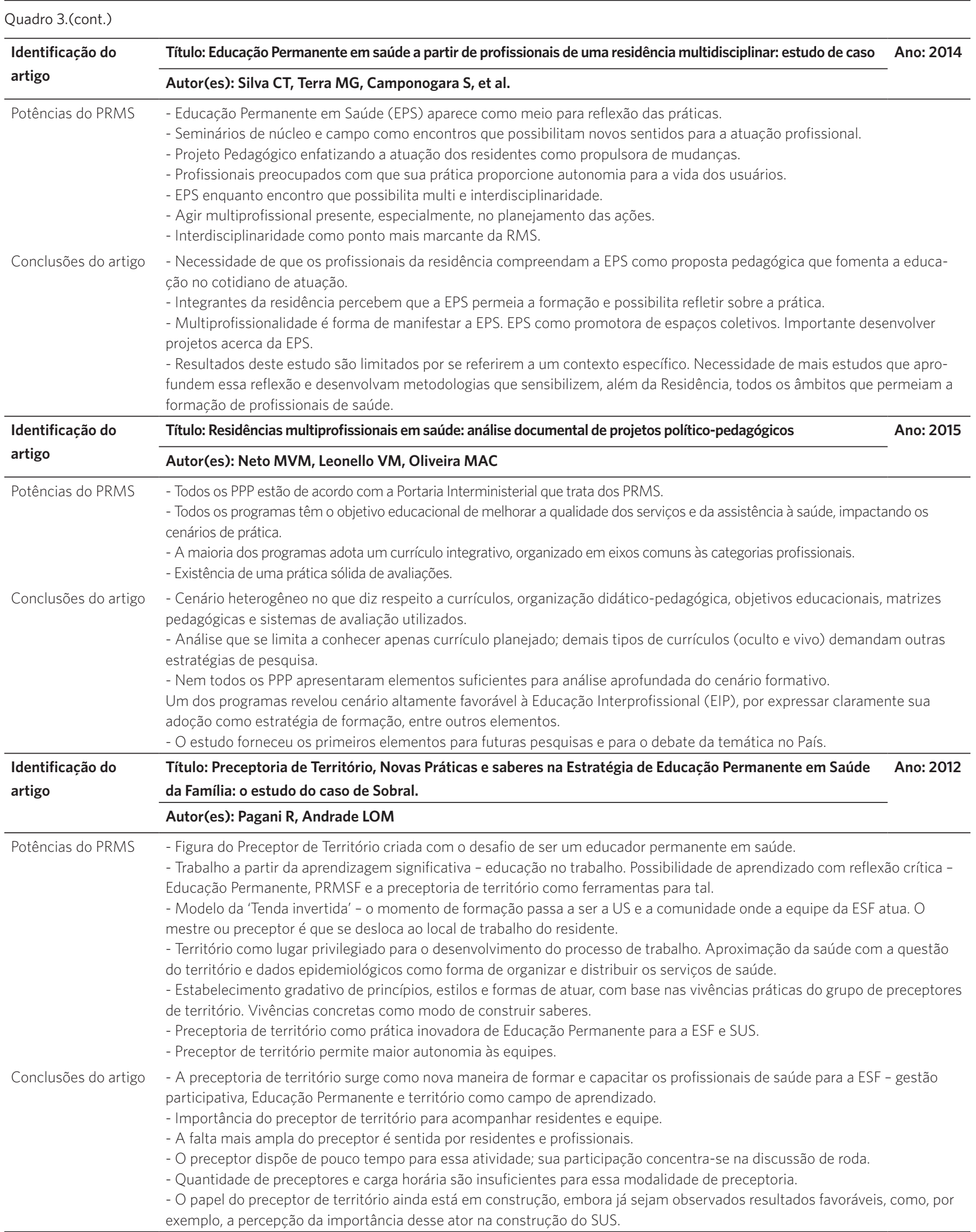


Quadro 3.(cont.)

\begin{tabular}{|c|c|}
\hline \multirow{2}{*}{$\begin{array}{l}\text { Identificação do } \\
\text { artigo }\end{array}$} & Título: Pós-graduação multiprofissional em saúde: resultados de experiências utilizando metodologias ativas \\
\hline & Autor(es): Marin MJS, Gomes R, Marvulo MML, et al. \\
\hline cias do PRMS & $\begin{array}{l}\text { - Os cursos estimularam mudanças efetivas no comportamento dos estudantes e na sua prática profissional cotidiana. } \\
\text { - Cursos proporcionaram qualificação para o trabalho na área do curso. Os cursos obtiveram êxito na formação baseada em } \\
\text { competência profissional. } \\
\text { - Curso que utiliza metodologias ativas pode ser avaliado como exitoso quando proporciona integralidade e articulação teo- } \\
\text { ria-prática. } \\
\text { Os êxitos apontados pelos egressos na formação ancoram-se nas dimensões cognitiva, afetiva e psicomotora - articulação } \\
\text { entre pensar, sentir e agir. } \\
\text { - Curso proporcionou sólida formação teórica e prática, preparo para trabalho em equipe e conhecimento sobre os princípios } \\
\text { das políticas públicas de atenção à saúde. Formação potente tanto no coletivo quanto nas especialidades. } \\
\text { - Articulação entre saber e fazer consolida a graduação. } \\
\text { - O curso possibilita conhecer o fazer de outras categorias e a capacidade de resolução de conflitos no processo de trabalho. } \\
\text { - Os egressos apontam que há coerência entre os princípios do SUS e os Projetos Pedagógicos dos cursos. } \\
\text { - Enfoque na interdisciplinaridade - possibilita parcerias produtivas. Possibilidade de transformação nos ambientes de trabalho. } \\
\text { - Possibilita mudar visão dos usuários para além das doenças ou do seu corpo - clínica ampliada. }\end{array}$ \\
\hline Conclusões c & $\begin{array}{l}\text { - Dificuldade de generalização dos achados - pesquisa em um único local e poucos participantes que não representam o } \\
\text { universo de egressos. } \\
\text { - Os egressos compreenderam, em grande parte, as dimensões que devem ser consideradas na formação de um novo profis- } \\
\text { sional mais próximo dos princípios e diretrizes do SUS. } \\
\text { - Metodologias ativas como modo que possibilita visão ampliada da realidade e articulação teoria-prática, além da capacida- } \\
\text { de de conviver e respeitar diferentes saberes necessários ao cuidado integral. } \\
\text { - Os achados da pesquisa convergem com um ensaio teórico que conclui que as modalidades de ensino podem representar } \\
\text { um movimento inovador no contexto da educação na área da saúde, favorecendo as mudanças necessárias na implementa- } \\
\text { ção dos princípios do SUS. } \\
\text { - No cotidiano dos serviços ainda há uma distância entre o preconizado e o realizado. Necessidade de maior reflexão sobre } \\
\text { Educação Permanente. } \\
\text { - Maior investimento na área de competência de gestão e organização dos serviços - diminuir distância entre cotidiano e } \\
\text { política de saúde. } \\
\text { - Necessidade de continuidade do investimento no processo educativo. } \\
\text { - É possível trabalhar com metodologias ativas e a interação de profissionais de diferentes áreas, a fim de impulsionar mu- } \\
\text { danças na formação iluminadas por um novo olhar do processo ensino-aprendizagem. }\end{array}$ \\
\hline \multirow{2}{*}{$\begin{array}{l}\text { Identificação do } \\
\text { artigo }\end{array}$} & Título: Residências em Saúde: o que há nas produções de teses e dissertações? \\
\hline & Autor(es): \\
\hline Potências do PRMS & $\begin{array}{l}\text { - Residências apontadas como dispositivos de Educação Permanente e modalidade importante para formar trabalhadores da } \\
\text { saúde - potencial pedagógico. } \\
\text { - Integralidade aparece como importante vetor para configurar as Residências como estratégia de educação no trabalho. } \\
\text { - Residência possibilita aprimoramento técnico-científico dos profissionais em formação. }\end{array}$ \\
\hline Conclusões do artigo & $\begin{array}{l}\text { - Há predominância de pesquisas sobre as Residências Médicas, devido ao fato de estarem há mais tempo instituídas legal- } \\
\text { mente no Brasil. } \\
\text { - As concepções tradicionais de educação são ao mesmo tempo limites e potências para operar a mudança na formação. } \\
\text { - Expressivo número de pesquisas que buscaram avaliar programas em andamento. } \\
\text { - A discussão propõe a criação de um novo descritor que seja integrador, ou seja, adequado às pesquisas sobre Residência } \\
\text { Médica, Multiprofissional e em área profissional - descritor proposto: 'Residências em Saúde'. }\end{array}$ \\
\hline
\end{tabular}

Fonte: Elaboração própria.

\section{Aspectos estruturais das institui- ções/campos de prática dos PRMS}

\author{
As publicações agrupadas nessa categoria ${ }^{32,33-37}$ \\ assinalam, entre outras questões, a ausência de
}

recursos para o trabalho na AP, porém, nestes serviços, os autores identificam assistência mais humanizada aos usuários. Por outro lado, citam o trabalho na atenção terciária como fragmentado, individualizado e centrado em 
procedimentos técnicos, porém, com recursos para o trabalho. Os autores também apontam que o excesso de encaminhamentos da AP para outros serviços denuncia a insuficiência de recursos no nível primário de atenção à saúde.

Quanto aos aspectos positivos, os artigos destacam que há avançado aporte de recursos tecnológicos (na atenção terciária) à disposição do PRMS, o que possibilita o aprimoramento do conhecimento científico e tecnológico em saúde, através das atividades de ensino, pesquisa e assistência. A Residência potencializa a ESF como dispositivo de mudança na atenção à saúde; fomenta o avanço do trabalho multiprofissional nos serviços; inclui diversas categorias profissionais que não atuavam nas Unidade de Saúde da Família (USF); e amplia o conhecimento dos trabalhadores sobre território e dados epidemiológicos, melhorando o planejamento das ações. Os estudos também afirmam que o fortalecimento do trabalho entre equipe das USF e residentes se deu após a contratação de profissionais via concurso público ${ }^{34,35}$.

Alguns estudos ${ }^{21,35}$ também concluem que o PRMS ajuda a evidenciar a insuficiência da equipe mínima da ESF e da estrutura dos serviços e apontam como solução a necessidade de urgência no comprometimento dos gestores para melhora das deficiências apontadas. Além disso, a parceria ensino, serviço e comunidade se faz necessária para consolidação do PRMS como estratégia de mudança na formação dos trabalhadores da saúde.

De maneira geral, o PRMS possibilita, segundo as publicações, mudanças efetivas no comportamento e nas práticas dos residentes; fornece qualificação na área/eixo do programa; êxitos nas dimensões cognitiva, afetiva e psicomotora - pensar, sentir e agir dos residentes; articulação entre saber e fazer, ajudando a consolidar a formação acadêmica; conhecimento acerca do fazer de outras categorias profissionais, fomentando a interdisciplinaridade e a formação de parcerias produtivas; além de auxiliar na identificação das potências e dos limites de cada serviço.

Outra contribuição do PRMS está na possibilidade de transformações nos serviços e atuação baseada na clínica ampliada ${ }^{\mathbf{2 1 2 7}}$. Os PRMS são apontados como dispositivos importantes para formar trabalhadores da saúde com base na Educação Permanente em Saúde (EPS), sendo um vetor importante da educação pelo trabalho ${ }^{12}$. A EPS aposta na ideia de que o trabalho é um elemento fundamental para que haja aprendizagem significativa, fomentando um movimento que coloca o trabalho em análise, visando a definir prioridades que promovam a reorganização dos espaços de produção de saúde. A EPS é tomada como uma importante estratégia de formação dos profissionais de saúde a partir da problematização do trabalho ${ }^{36}$.

\section{Considerações finais}

Esta pesquisa possibilitou uma visão abrangente dos principais elementos que perpassam o PRMS em discussão, no período de 2010 a 2015. Contribuiu, ainda, para dar visibilidade às publicações e incentivo à sua leitura, sintetizando as diversas realidades destacadas por elas.

Ao propor um movimento de análise das temáticas que permeiam os Programas, este estudo não pretende esgotar a discussão, tampouco realizar uma abordagem sob uma perspectiva dicotômica. O intuito foi destacar os aspectos que devem ser avaliados e os que devem ser fortalecidos na trajetória de construção do PRMS. Por isso, é imprescindivel analisar tais elementos de maneira articulada aos determinantes macropolíticos, considerando que as concepções acerca do processo saúde-doença e a estruturação da política pública de saúde, bem como dos programas que dela derivam, são influenciadas pelas formas de organização social na quais se desenvolvem.

A posição particular da autora possibilitou identificar as mesmas problemáticas e potências no Programa ao qual está ligada como residente, ainda que com nuances diferenciadas, devido a particularidades regionais, das 
instituições abordadas e dos profissionais em questão. Possibilitou, ainda, perceber que os dilemas vivenciados nos PRMS não estão isolados e acompanham uma realidade nacional, diretamente ligada à estrutura política, social e econômica brasileira. Porém, também vale alertar para o protagonismo e a autonomia relativa dos sujeitos nos processos em que se inserem. Em outras palavras, é possível pensar estratégias que humanizem as relações de trabalho, pois é justamente nesta dimensão - a dos processos de trabalho - que se pode evidenciar o posicionamento ético, político e o compromisso com os ideais do Projeto de Reforma Sanitária para o SUS. Dito isso, cabe ressaltar que o PRMS ainda é novo e tem possibilidades de construção ainda em aberto, que devem ser estrategicamente aproveitadas.

As publicações, em síntese, evidenciaram uma realidade consolidada de hegemonia do modelo biomédico de saúde e precarização das condições de trabalho e estrutura dos serviços. Essa realidade impacta diretamente as relações interpessoais e institucionais estabelecidas entre os residentes e trabalhadores das instituições, bem como a sua formação e sua prática profissional. Contudo, é importante ressaltar que as estratégias para enfrentamento dessas problemáticas e para transformação da realidade também têm sido fomentadas pelos que acreditam nas potencialidades do PRMS e no SUS como política pública que constitui direito a ser defendido. Neste sentido, destaca-se que a construção de alternativas que qualifiquem a formação em saúde deve considerar a importância de todos os atores que constituem o cenário da saúde pública brasileira. Trata-se da fundamental importância de considerar as instâncias de controle e participação social, dando voz à população usuária dos serviços e integrando-a nas discussões que objetivam consolidar o PRMS, em consonância com os princípios do SUS.

\section{Colaboradores}

Silva CA (0000-0001-8565-5660)* contribuiu para a concepção e o planejamento; análise e interpretação dos dados; elaboração do rascunho; e aprovação da versão final do manuscrito. Dalbello-Araujo M (0000-0002-9950-3358)* contribuiu para a concepção e o planejamento; revisão crítica do conteúdo; e aprovação da versão final do manuscrito. 


\section{Referências}

1. Campos FE, Pierantoni CR, Haddad AE, et al. Os desafios atuais para a educação permanente no SUS. In: Brasil. Ministério da Saúde. Cadernos RH Saúde. Brasília, DF: Ministério da Saúde; 2006. p. 41-45.

2. Heckert AL, Neves CAB. Modos de formar e modos de intervir: quando a formação se faz potência de produção de coletivo. In: Brasil. Ministério da Saúde. Secretaria de Atenção à Saúde. Cadernos Humaniza SUS. Brasília, DF: Ministério da Saúde; 2010. p. 14-28.

3. Silva LB, Capaz R. Preceptoria: uma Interface entre Educação e Saúde no SUS. In: Silva LB, Ramos A, organizadoras. Serviço Social, saúde e questões contemporâneas: reflexões críticas sobre a prática profissional. São Paulo: Papel Social; 2013. p. 201-215.

4. Rosa SD, Lopes RE. Residência Multiprofissional em Saúde e Pós-graduação lato sensu no Brasil: apontamentos históricos. Revista Trab. Educ. Saúde [internet]. 2010 [acesso 2018 nov 15]; 7(3):479-498. Disponível em: http://www.scielo.br/pdf/tes/v7n3/06.pdf.

5. Brasil. Ministério da Educação; Ministério da Saúde. Portaria $\mathrm{n}^{\mathrm{o}} 45$, de 12 de janeiro de 2007. Dispõe sobre a Residência Multiprofissional em Saúde e a Residência em Área Profissional da Saúde e institui a Comissão Nacional de Residência Multiprofissional em Saúde. Diário Oficial da União. 15 Jan 2007.

6. Brasil. Ministério da Educação; Ministério da Saúde. Portaria $\mathrm{n}^{\circ}$ 1.077, de 12 de novembro de 2009. Dispõe sobre a Residência Multiprofissional em Saúde e a Residência em Área Profissional da Saúde, e institui o Programa Nacional de Bolsas para Residências Multiprofissionais e em Área Profissional da Saúde e a Comissão Nacional de Residência Multiprofissional em Saúde. Diário Oficial da União. 13 Nov 2009.

7. Brasil. Ministério da Educação; Ministério da Saúde. Portaria $n^{\circ} 1.224$, de 03 de outubro de 2012. Altera a Portaria Interministerial $\mathrm{n}^{\circ} 1.077$, de 12 de novembro de 2009, e a Portaria Interministerial n ${ }^{\circ} 1.320$, de 11 de novembro de 2010, que dispõem sobre a Comissão Nacional de Residência Multiprofissional em Saúde - CNRMS. Diário Oficial da União. 4 Out 2012.

8. Mendes AG. Residência Multiprofissional em Saúde e Serviço Social. In: Silva LB, Ramos A, organizadoras. Serviço Social, saúde e questões contemporâneas: reflexões críticas sobre a prática profissional. São Paulo: Papel Social; 2013. p. 183-199.

9. Brunholi GN. Caminhando pelo fio da história: a Residência Multiprofissional em Saúde nos espaços de construção da política de formação de trabalhadores para o SUS [dissertação] [internet]. Vitória: Universidade Federal do Espírito Santo; 2013. 200 p. [acesso em 2018 nov 10]. Disponível em: http://repositorio. ufes.br/bitstream/10/1284/1/Dissertacao\%20Gislene\%20do\%20Nascimento\%20Brunholi.pdf.

10. Sá-Silva JR, Almeida CD, Guindani JF. Pesquisa documental: pistas teóricas e metodológicas. Rev Bras. História Ciênc. Soc. [internet]. 2009 [acesso 2018 nov 10]; 1(1):1-15. Disponível em: https://www.rbhcs.com/ rbhcs/article/view/6/pdf.

11. Dallegrave D, Ceccim RB. Residências em Saúde: o que há nas produções de teses e dissertações? Interface (Botucatu) [internet]. 2013 [acesso 2018 nov 10]; 17(47):759-775. Disponível em: http://www.scielo.br/ pdf/icse/v17n47/aop4113.pdf.

12. Manho F, Soares LBT, Nicolau SM. Reflexões sobre a prática do residente terapeuta ocupacional na estratégia saúde da família no município de São Carlos. Rev. Terapia Ocupac. USP [internet]. 2013 [acesso 2017 out 20]; 24(3):233-241. Disponível em: http:// dx.doi.org/10.11606/issn.2238-6149.v24i3p233-41.

13. Moura RFS, Silva CRC. Saúde mental na Atenção Básica: sentidos atribuídos pelos agentes comunitários de saúde. Psicologia: Ciênc. Prof. [internet]. 2015 [acesso 2018 nov 12]; 35(1):199-210. Disponível em: http://www.scielo.br/pdf/pcp/v35nl/1414-9893pcp-35-01-00199.pdf. 
14. Fernandes MNS, Beck CLC, Weiller TH, et al. Sofrimento e prazer no processo de formação de residentes multiprofissionais em saúde. Rev. Gaúcha de Enfer. [internet]. 2015 [acesso em 2017 out 20]; 36(4):9097. Disponível em: http://dx.doi.org/10.1590/19831447.2015.04.50300.

15. Mendes AMB. Aspectos Psicodinâmicos da Relação Homem-Trabalho: as contribuições de C. Dejours. Psicologia: Ciênc. Prof. [internet]. 1995 [acesso 2018 nov 12]; 15(1-3):34-38, 1995. Disponível em: http:// www.scielo.br/pdf/pcp/v15nl-3/09.pdf.

16. Brites LS, Weiller TH, Silevira D, et al. "A gente vai aprendendo": o apoio matricial na estratégia de saúde da família em um programa de residência multiprofissional integrada no interior do Rio Grande do Sul, Brasil. Saúde debate [internet]. 2014 [acesso 2017 out 20]; 38(101):285-295. Disponível em: https://www.lume. ufrgs.br/bitstream/handle/10183/110282/000950510. pdf?sequence $=1$.

17. Guido LA, Silva RM, Goulart CT, et al. Síndrome de Burnout em residentes multiprofissionais de uma universidade pública. Rev. Escola de Enfermagem da USP [internet]. 2012 [acesso 2017 out 20]; 46(6):1477-1483. Disponível em: http://www.scielo.br/pdf/reeusp/ v46n6/27.pdf.

18. Nascimento DDG, Oliveira MMC. Competências Profissionais e o Processo de Formação na Residência Multiprofissional em Saúde da Família. Saúde Soc. [internet]. 2010 [acesso 2017 out 20]; 19(4):814827. Disponível em: http://www.scielo.br/scielo. php?pid=S0104-12902010000400009\&script=sci abstract\&tlng=pt.

19. Zanin LE, Albuquerque IMN, Melo DH. Fonoaudiologia e estratégia de saúde da família: implicação da dimensão estrutural na qualidade da atenção à saúde fonoaudiológica. Audiol. Commun. Res. [internet]. 2015 [acesso 2017 out 20]; 20(3):255-261. Disponível em: http://www.scielo.br/scielo.php?script=sci_ abstract\&pid=S2317-64312015000300255\&lng=en\& $\mathrm{nrm}=\mathrm{iso} \&$ tlng=pt.

20. Santos IG, Batista NA, Devincenzi MU. Residência
Multiprofissional em Saúde da Família: concepções de profissionais de saúde sobre a atuação do nutricionista. Interface Comun. Saúde Edu. [internet]. 2015 [acesso 2017 out 20]; 19(53):349-360. Disponível em: http://www.scielo.br/scielo.php?pid=S1414$-32832015000200349 \&$ script=sci_abstract\&tlng=pt.

21. Gomes JA, Brito CMD. Apoio matricial e terapia ocupacional: uma experiência de abordagem na saúde da criança. Rev. Terapia Ocupacional da USP [internet]. 2013 [acesso 2017 out 20]; 24(1):81-86. Disponível em: https://www.revistas.usp.br/rto/article/download/61994/pdf_2/.

22. Zanin LE, Albuquerque IMN, Melo DH. Fonoaudiologia e estratégia de saúde da família: o estado da arte. Rev. CEFAC [internet]. 2015 [acesso 2017 out 20]; 17(5):1674-1688. Disponível em: http://www.scielo. br/pdf/rcefac/v17n5/1982-0216-rcefac-17-05-01674. pdf.

23. Rossoni E. Residência na atenção básica à saúde em tempos líquidos. Physis [internet]. 2015 [acesso 2017 out 20]; 25(3):1011-1031. Disponível em: http://www. scielo.br/scielo.php?script=sci_arttext\&pid=S0103$-73312015000301011 \& \operatorname{lng}=$ pt\&tlng=pt.

24. Oliveira FGVC, Carvalho MAP, Garcia MRG, et al. A experiência dos diários reflexivos no processo formativo de uma Residência Multiprofissional de Saúde da Família. Interface Comunicação Saúde Educação [internet]. 2013 [acesso 2017 out 20]; 17(44):201-209. Disponível em: http://www.scielo. br/pdf/icse/2013nahead/aop0213.

25. Marin MJS, Gomes R, Marvulo MML, et al. Pós-graduação multiprofissional em saúde: resultados de experiências utilizando metodologias ativas. Interface Comum. Saúde Edu. [internet]. 2010 [acesso 2017 out 20]; 1(33):331-344. Disponível em: http://www.scielo.br/scielo.php?pid=S1414$-32832010000200008 \&$ script=sci_abstract\&tlng=pt.

26. Lana LD, Birner JA. Um relato de caso sobre a construção e elaboração do portfólio como metodologia avaliativa de aprendizagem. Rev. Ciencia Enfer. [internet]. 2015 [acesso 2017 out 20]; (3):1010-112. Dis- 
ponível em: https://scielo.conicyt.cl/pdf/cienf/v2ln3/ art_09.pdf.

27. Autônomo FROM, Hortale VA, Santos GB, et al. A Preceptoria na Formação Médica e Multiprofissional com Ênfase na Atenção Primária - Análise das Publicações Brasileiras. Rev. Brasileira de Educação Médica [internet]. 2015 [acesso 2017 out 20]; 39(2):316-327. Disponível em: http://www.scielo.br/scielo.php?pid=S0100$-55022015000200316 \&$ script=sci_abstract\&tlng=es.

28. Melo MC, Queluci GC, Gouvêa MV. Problematizando a residência multiprofissional em oncologia: protocolo de ensino prático na perspectiva de residentes de enfermagem. Rev. Escola de Enfer. USP [internet]. 2014 [acesso 2017 out 20]; 48(4):706-714. Disponível em: http://www.scielo.br/pdf/reeusp/v48n4/ pt_0080-6234-reeusp-48-04-706.pdf.

29. Pagani R, Andrade LOM. Preceptoria de Território, novas práticas e saberes na estratégia de Educação Permanente em saúde da família: o estudo do caso de Sobral, CE. Saúde Soc. [internet]. 2012 [acesso 2017 out 20]; 21(supl1):94-106. Disponível em: http://www. scielo.br/pdf/sausoc/v21s1/08.pdf.

30. Neto MVM, Leonello VM, Oliveira MAC. Residências multiprofissionais em saúde: análise documental de projetos político-pedagógicos. Rev. Brasileira Enfer. [internet]. 2015 [acesso 2017 out 20]; 68(4):586593. Disponível em: http://www.scielo.br/pdf/reben/ v68n4/0034-7167-reben-68-04-0586.pdf.

31. Vasconcelos MIO, Souza FL, Lira GV, et al. Avaliação de programas de residência multiprofissional em saúde da família por indicadores. Trab. Educ. Saúde [internet]. 2015 [acesso 2017 out 20]; 13(supl2):5377. Disponível em: http://www.scielo.br/scielo. php?pid=S1981-77462015000500053\&script $=$ sci $_{-}$ abstract\&tlng=pt.

32. Domingos CM, Nunes EFPA, Carvalho BG. Potencialidades da Residência Multiprofissional em Saúde da Família: o olhar do trabalhador de saú- de. Interface Comunic. Saúde Edu. [internet]. 2015 [acesso 2017 out 20]; 19(55):1221-1232. Disponível em: https://www.scielosp.org/scielo.php?pid=S1414$-32832015000601221 \&$ script=sci_arttext.

33. Silva CTS, Terra MG, Camponogara S, et al. Educação permanente em saúde a partir de profissionais de uma residência multidisciplinar: estudo de caso. Rev. Gaúcha Enfer. [internet]. 2014 [acesso 2017 out 20]; 35(3):49-54. Disponível em: https://seer.ufrgs.br/ RevistaGauchadeEnfermagem/article/view/44512.

34. Aredes MA, Bahia LA, Silva CSMC, et al. A comunicação entre a equipe de saúde em uma clínica cirúrgica: o olhar dos profissionais de um Programa de Residência Multiprofissional em Saúde. J. Of Research: Fund. Care [internet]. 2013 [acesso em 2017 out 20]; 5(4):458-466. Disponível em: http://www.scielo.br/ pdf/tes/v7n3/06.pdf.

35. Cezar PK, Rodrigues PM, Arpini DM. A Psicologia na Estratégia de Saúde da Família: Vivências da Residência Multiprofissional. Psic. Ciênc. Prof. [internet]. 2015 [acesso em 2017 out 20]; 35(1):211-224. Disponível em: http://dx.doi.org/10.1590/1982-3703000012014.

36. Pinto EEP, Araújo MD, Matumoto S, et al. Desdobramentos da Educação Permanente em Saúde no Município de Vitória, Espírito Santo. Trab. Educ. Saúde [internet]. 2010 [acesso 2017 out 20]; 8(1):77-96. Disponível em: http://www.scielo.br/pdf/tes/v8nl/05. pdf.

37. Silva JC, Contim D, Ohl RIB, et al. Percepção dos residentes sobre sua atuação no programa de residência multiprofissional. Acta Paulista de Enfer. [internet]. 2015 [acesso 2017 out 20]; 28(2):132-138. Disponível em: http://www.scielo.br/scielo.php?pid=S0103$-21002015000200132 \&$ script=sci_abstract\&tlng=es.

Recebido em 28/03/2019

Aprovado em 06/10/2019

Conflito de interesses: inexistente

Suporte financeiro: não houve 